\title{
Common ground, complex problems and decision making
}

Citation for published version (APA):

Beers, P., Boshuizen, E., Kirschner, P. A., \& Gijselaers, W. (2006). Common ground, complex problems and decision making. Group Decision and Negotiation, 15(6), 529-556. https://doi.org/10.1007/s10726-006-9030-1

DOI:

10.1007/s10726-006-9030-1

Document status and date:

Published: 25/07/2006

Document Version:

Peer reviewed version

Please check the document version of this publication:

- A submitted manuscript is the version of the article upon submission and before peer-review. There can be important differences between the submitted version and the official published version of record. People interested in the research are advised to contact the author for the final version of the publication, or visit the DOI to the publisher's website.

- The final author version and the galley proof are versions of the publication after peer review.

- The final published version features the final layout of the paper including the volume, issue and page numbers.

Link to publication

\section{General rights}

Copyright and moral rights for the publications made accessible in the public portal are retained by the authors and/or other copyright owners and it is a condition of accessing publications that users recognise and abide by the legal requirements associated with these rights.

- Users may download and print one copy of any publication from the public portal for the purpose of private study or research.

- You may not further distribute the material or use it for any profit-making activity or commercial gain

- You may freely distribute the URL identifying the publication in the public portal.

If the publication is distributed under the terms of Article 25fa of the Dutch Copyright Act, indicated by the "Taverne" license above, please follow below link for the End User Agreement:

https://www.ou.nl/taverne-agreement

Take down policy

If you believe that this document breaches copyright please contact us at:

pure-support@ou.nl

providing details and we will investigate your claim.

Downloaded from https://research.ou.nl/ on date: 26 Apr. 2023 


\title{
Common Ground, Complex Problems and Decision Making
}

PIETER J. BEERS

Faculty of Technology, Policy and Management, Delft University of Technology/Education Technology Expertise Center, Open University of the Netherlands

(E-mail:p.j.beers@tudelft.nl)

HENNY P. A. BOSHUIZEN

Education Technology Expertise Center, Open University of the Netherlands

PAUL A. KIRSCHNER

Research Centre for Interaction and Learning, Utrecht University/Education Technology Expertise Center, Open University of the Netherlands

WIM H. GIJSELAERS

Department of Educational Development and Educational Research, Maastricht University

\begin{abstract}
Organisations increasingly have to deal with complex problems. They often use multidisciplinary teams to cope with such problems where different team members have different perspectives on the problem, different individual knowledge and skills, and different approaches on how to solve the problem. In order to solve those problems, team members have to share their existing knowledge and construct new knowledge. Theory suggests that negotiation of common ground can positively affect team decision making on the solution of complex problems, by facilitating knowledge sharing across perspectives. In a small scale study with student groups, external representations supported by a specific negotiation ontology were used to facilitate negotiation by encouraging participants to make their beliefs and values explicit. Results showed that the external representations supported clarifying contributions to group members and increased group participation in discussions.
\end{abstract}

Key words: complex problems, common ground, negotiation of meaning, negotiation of position, decision making, decision support, ICT-tools

The many-sidedness of complex societal problems underlines the need for rich problem conceptualisations, and thus the need for multidisciplinary and multi-stakeholder approaches. However, forming heterogeneous teams to solve complex problems is no guarantee for a good solution since, especially in the case where teams are formed to include different perspectives, team members can have difficulties in understanding each other and in sharing knowledge. Bromme, Rambow and Nückles (2001) found that people tend to make biased estimates about the knowledge of their discussion partners, which may result in ample explanations of what is widely known, or ignorance or misunderstanding. Bechky (2003) 
found that problems on the work floor caused misunderstandings between workers from different departments due to their different perspectives. Bechky noted that in order to solve the work floor problems, different workers would first negotiate some common ground (i.e., a common frame of reference) to bridge the differences in perspective and be able to share knowledge from their different viewpoints.

Much effort has been expended in the development of decision support-tools for the facilitation of complex problem solving. Traditionally, these tools aimed at facilitating formal and informal communication, harvesting knowledge, and building knowledge repositories (Courtney 2001). However, they did not facilitate bridging the gaps between different perspectives. As Hasan and Gould (2001) lament: "There has been an unfortunate tendency to view both the computerised information systems and the decision makers as comparable information processors" (p. 71). A different decision support-approach is needed to meet the requirements of facilitating complex problem solving.

Recent approaches to decision-support rooted in operational research use aspects of problem structure as a basis for the development of decision support. For example, group model building (Vennix 1996) is a means to capture the structure and behaviour of a specific class of complex systems, namely information feedback systems, in which decisions affect the decision environment in such ways that long-term effects of a particular decision may radically differ and even counteract short-term effects. The strategic choice approach (Friend and Hickling 1987; Friend 2001; Hickling 2001), also an example of a problem structuring method, is a planning methodology rooted in notions about uncertain knowledge about and interconnectedness of complex problems and how to cope with them. These Group Decision Support Systems have many and different aims, but share the need for successful negotiation processes (Eden 1992). Indeed, they often use techniques such as transitional or visual interactive modelling that require common ground, and in that way implicitly facilitate its negotiation (e.g., Vennix; Richardson and Anderson 1995). However, their design does not explicitly take the negotiation of common ground into account.

Fisher and Ury (1982) detail the importance of principled negotiation processes. They show that even when large differences of position are present, for example in the case of diplomatic issues, it is important to try and see the problem from the other's perspective instead of focusing on the other's position. This principle of negotiation indicates a notion of negotiating common ground before negotiating an entire solution/deal. In other words, it is not just negotiation that is important to complex problem solving, but especially the way negotiation takes place.

This article approaches decision support as a group-processes phenomenon. It presents a framework for designing decision support for complex problem solving in multidisciplinary teams, and proposes a methodology for testing these designs. First some aspects of complexity and multidisciplinarity are dealt with. Then the framework is described, with an emphasis on theory about common ground (Bromme 2000). It is argued that negotiating common ground can be afforded by making individual team members' perspectives explicit to the others.

From this framework a set of primitives, basic building blocks (Dillenbourg 2002) for the design of decision support, is derived. The overarching question discussed in this article 


\section{COMMON GROUND AND DECISION MAKING}

is how to design tools for the externalisation of individual perspectives, and how to measure their effects.

The second part of this article reports on a small scale study aimed at making the process of grounding visible and whereby an attempt was made to measure common ground in six student groups.

\section{Complexity}

Whereas traditional problems can be solved with knowledge from one discipline, occur within one societal sector, and involve only one actor, complex societal problems occur across multiple scientific disciplines and societal sectors, involve multiple actors and stakeholders, and can be seen as a web of problems (Rotmans 1998; Van Asselt 2000). For example, the problem of high-school drop-out can be conceptualised as pedagogical, social, economic, and legal in nature. Furthermore, the interests of a variety of actors are at stake, namely children, parents, teachers, politicians, et cetera.

Complex societal problems are inherently "wicked" (Rittel and Webber 1973). This means that "solutions" to such problems usually cannot be tried out, so aspects like plausibility and acceptability of information play an important role in problem solving. Furthermore, one "solution" is often either incomplete, and/or unacceptable since it does not or cannot take into account the effects on, and the problems of all other stakeholders. Solving complex problems involves making "tough decisions" (Nutt 2002); decision makers face ambiguity, uncertainty, and conflict. They can no longer follow a single claim about the nature of the problem at hand and its solution, but instead have to consider several problem perspectives, and search for solutions accordingly.

Lomi et al. (1997) argue that mono-disciplinary approaches to solving such problems generally lead to adaptive or incremental solutions which remain within the boundaries of one (the current) perspective on the problem. More importantly, they fail to generate those innovative solutions necessary for coping with societal complexity; solutions which cross disciplinary boundaries and take multiple perspectives on the problem into account. Indeed, Nutt (2002) writes that decision makers who explore the claims of the various experts and stakeholders involved tend to be more successful that those that choose one problem perspective, which in a worst-case scenario may result in a debacle. It appears that different perspectives are needed to understand the breadth of complex problems. In sum, to deal with societal complexity, it is important to involve different perspectives on the problem.

\section{Multidisciplinarity}

Team members, based on their professional and personal background, will each have their own perspective, their own way in which they coherently and consistently "interpret and make sense of the world" (cf. Douglas and Wildavsky 1982; Van Asselt 2000). In multidisciplinary and multi-stakeholder teams, the members can bring their different perspectives 
to bear on the problem, resulting in multiple representations of the problem within one team. These different representations, when properly co-ordinated, can cater for a broad problem scope which assists teams in going beyond adaptive and incremental solutions (cf. Dillenbourg et al. 1995; Vennix 1996). However, different perspectives have also been shown to give rise to misunderstandings and disagreement among decision-making team members (e.g. Alpay et al. 1998; Boshuizen and Tabachneck-Schijf 1998; Bromme and Nückles 1998), threatening the decision-making process itself.

Members of multidisciplinary teams make use of language either not understood by those with other areas of expertise, or with a different meaning in another's field (Van Someren et al. 1998). People can make contributions which are evident from their own point of view, but not from the perspectives of other group members. This, in turn, can lead to either non-understanding or misunderstanding. If misunderstanding remains undetected and a team continues to work, multiple representations may come to equal 'multiple ignorances'. The team may not be able to construct a coherent problem representation at all, or only solve partial problems. It even runs the risk of unknowingly implementing contradictory solutions to the same problem. Bromme's (2000) theory of cognitive interdisciplinarity holds that common ground is an important condition for knowledge sharing among different perspectives.

\section{Decision Support}

The above shows that solving complex problems involves integrating knowledge from different perspectives about complex systems to arrive at robust solutions. Negotiation constitutes an important part of any support method for complex problem solving (Richardson and Anderson 1995). The negotiators have to understand each other's perspectives for negotiation processes from different perspectives to evolve effectively (Fisher and Ury 1982). It is thus important that negotiation must be seen as more than bartering. In the case of societal complexity, it is important to first understand each other. In other words, negotiation should start with the negotiation of common ground (Bromme 2000).

Modern Group Decision Support Systems include several tools that influence the way negotiation takes place. For instance, in the case of group model building (Vennix 1996), the group model that is constructed implicitly requires ownership by the whole group, which means that all group members need sufficient understanding of the whole model to achieve this. The same holds for Strategic Options Development and Analysis (SODA; Eden and Ackermann 2001), an approach that uses cognitive maps to capture group knowledge. The group model and the group cognitive map are both examples of transitional objects that facilitate negotiation processes. They make individual knowledge explicit and tangible to other group members

Many Group Decision Support Systems use transitional objects and interactive modeling techniques to represent a group's or team's ideas (Shaw Ackermann and Eden 2003). However, they do not explicitly facilitate the negotiation process and they can not guarantee that a group indeed negotiates sufficient common ground for solving the complex problem at hand. 


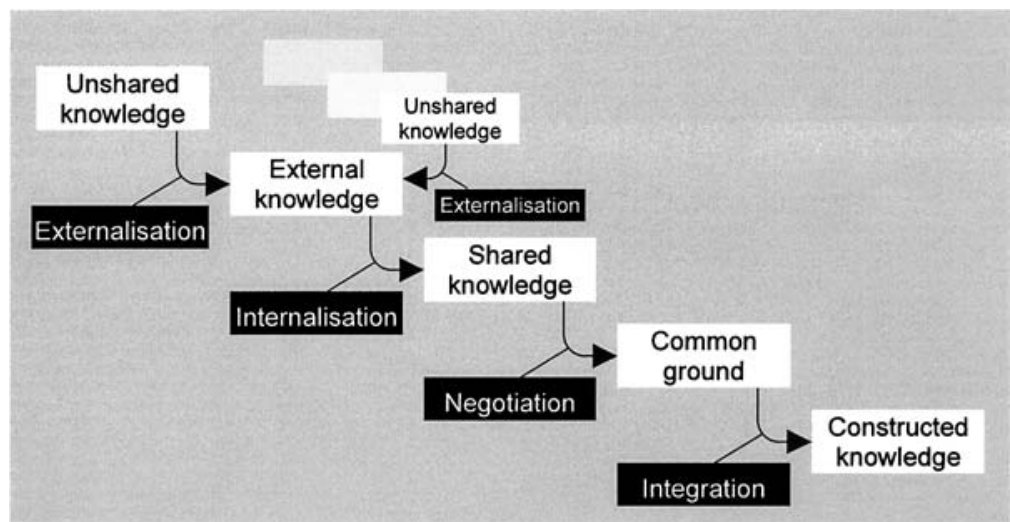

Figure 1. From unshared knowledge to constructed knowledge.

\section{A framework}

Our framework attempts to bring complex problem solving and multidisciplinary teamwork together by focusing on the various stages which take knowledge from being implicit in the mind of one person to becoming a team's explicit constructed knowledge.

The route from unshared knowledge in one participant's head to newly constructed knowledge in a team (see Figure 1) goes through three intermediate forms (i.e., external knowledge, shared knowledge, and common ground) via four processes (i.e., externalisation, internalisation, negotiation and integration).

Private knowledge is externalised when a team member makes his/her own, as yet unshared knowledge, explicit or tangible to others (Leontjev 1981). This can be oral, written, symbolic, et cetera. Once a team member has made a contribution, the others can all try to internalise this contribution. In doing so, they may consider aspects of the contributor such as background, current situation and possible views so as to better 'understand' the contribution. Also, their own beliefs and assumptions play a role while they try to understand the contribution. A contribution is thus understood against the presumed perspective of the other, as well as against one's own perspective (Bromme 2000). Note that problem structuring methods generally use a variety of knowledge externalisation techniques (e.g. cognitive mapping, causal mapping, oval mapping; Rosenhead and Mingers 2001; Vennix 1996) to capture argumentation, share views, and negotiate.

Externalising and subsequently internalising each others' knowledge does not mean that the team members have all arrived at the same understanding (Shaw et al. 2003). Representational differences result from interpreting a contribution only in one's own perspective (a graphical designer has a different understanding of, and use for the term 'elegance' than a computer programmer, see below) or from minimising or rejecting its validity or plausibility due to differences in conviction or opinion (an environmentalist may reject the corporate utterance on principle). Negotiation has to take place in order for a contribution to be accepted and agreed upon by the whole team (e.g. Dillenbourg et al. 1995; Alpay et al. 1998; Bromme 2000). 
As an example, imagine the following. A computer programmer and a graphical user interface designer are two members of a team designing a new user interface. At a certain point the programmer states that the chosen solution needs to be 'elegant'. The designer readily agrees, but to what? The programmer meant that the program needs to be as short as possible (her definition of elegance); the designer understood aesthetically pleasing (his definition of elegance). There is a problem here, but as yet it remains implicit and unseen, and no one can tell when it will surface, and how much damage it may cause in the interim. In other words, people may think they are on common ground while at the same time maintaining important representational differences. Such differences need to be detected before people can effectively start negotiating a shared representation to come to a solution.

Negotiation of common ground, also called grounding, is here conceived of as a dual concept. First there is negotiation of meaning, which, in the case of knowledge construction, leads to an agreement regarding meaning and understanding of a contribution. Negotiation of meaning concerns people making public to others their private understanding of some contribution, verifying whether and to what extent their own understanding is different from what others intended them to understand, receiving feedback on this, re-verifying, and so on. Negotiation of meaning is thus an iterative process that takes place until "the contributor and the partners mutually believe that the partners have understood what the contributor meant to a criterion sufficient for the current purpose" (Clark and Schaefer 1989, the grounding criterion). Note that the grounding criterion does not preclude situations where in fact people do not know on what they agree or disagree, or what the positions of the others are. The grounding criterion only concerns their beliefs, not their actual knowledge.

Negotiation of position is the second part of the negotiation concept. This concerns people making their private opinion about some contribution public to others, checking whether their own position is clear to others, and vice versa. It is through the process of internalising others' contributions, and subsequently providing feedback by word or action about those contributions based on one's own perspective, that common ground can be negotiated (Alpay et al. 1998; Baker et al. 1999). Common ground is never absolute or complete, but is an interactive and ongoing process in which assumed mutual beliefs and mutual knowledge are accumulated and updated (Clark and Brennan 1991).

Note that this account of grounding closely resembles Pettigrew's notion of management of meaning (1977), which is a process of seeking legitimacy for one's ideas. Management of meaning, as theorised by Pettigrew, occurs through joint symbol construction, which can be seen as an example of negotiation of meaning, and joint value use, which resembles negotiation of position.

Starting from the common ground, new knowledge can be built by adding new relations and concepts to the common ground, via integration. Knowledge construction is based on the common ground the team has built, and will broaden and deepen the common ground because the new commonly constructed knowledge becomes part of the common ground.

\section{Primitives of Negotiation}

Communication processes can be broken down into individual communication acts. A typology of communication acts then is a dialogue model. For example, Shaw et al. (2003) 
empirically derived communicative acts for knowledge sharing, thus modelling the process of knowledge sharing. Primitives can be seen as types of communication acts for a specific model of dialogue (Dillenbourg 2002), thus, primitives of negotiation would be derived from a dialogue model of negotiation, in which each primitive serves as a basic building block of the negotiation process. To make this clear, an idealised exemplary account of negotiation is presented and then used for identifying the primitives of negotiation.

Negotiation can start when someone has made a contribution (externalisation), and another has tried to pick it up (internalisation). When this has been done, a set of checks can be performed as to whether the discussion partners understand each other. The receiver compares what s/he thinks the contributor intended to say with his/her own understanding of the contribution, verifies this understanding (often with a question or rebuttal), and upon receiving feedback decides if there are no important differences between his/her own understanding and the contribution. The next step is deciding whether there is agreement. The receiver of a contribution can either agree with the contributor or hold an opposing opinion. Ideally negotiation continues until all negotiators think they understand each other sufficiently, and either hold the same position or can sufficiently respect an opposing position. Note here that this does not mean that they assume the other's position. They respect it and can agree to disagree.

The above account of negotiation can be used to derive some "basic building blocks" or "primitives" of negotiation. Negotiation starts with a contribution of some sort such as an idea or a position. A contribution does not stand on its own; rather it is based upon ideas, experience, and background of the contributor. Every contribution can therefore be underpinned by some sort of clarification by the contributor, which sheds light on the meaning of the contribution, or the opinion of the contributor. This clarification can remain implicit, for example, when the known background of the contributor sheds light on his/her contribution, but it can also be made explicit. Clarifications are usually needed because contributions are often not understood by the others in the way the contributor intended them to be. In other words, the meaning behind the message is not by definition clear (Fischer and Ostwald 2003).

Third, verification is needed for contributions to check the understanding of a contribution because people articulate and understand the contribution against their own background knowledge (Bromme 2000). A clarification is performed by the contributor, whereas the verification is performed by the one who is trying to understand the contribution.

A fourth element is acceptance/rejection of a contribution. This refers to whether one judges a contribution as true (acceptance), based on the explanation given, or as untrue or unintelligible (rejection). The fifth and last primitive requires every negotiator to decide upon a position regarding the contribution. This includes the possibility of accepting a certain contribution, but disagreeing all the same, for example when neither person can prove the other wrong. In such cases, people can agree to disagree, and alternate representations that are equally legitimate can ensue.

Note that this procedure entails some aspects of procedural justice, which is "the fairness of the process by which decisions are arrived at," (Kim and Mauborgne 1995, p. 44) 
in that it facilitates bilateral communication between people with different perspectives, without favouring any perspective. Specifically, the procedure is in line with some of the procedural justice design guidelines described by Kim and Mauborgne, which suggest that this procedure might increase compliance with strategic decisions.

\section{External representations for supporting negotiation}

Representations of abstract concepts exist in many cases partly in our heads, in which case they are called internal representations, and/or partly in our environment and are called external representations (Alpay et al. 1998). People can externalise their internal representations to a certain extent, and capture them externally. External representations can take many forms. The most common are self-made, idiosyncratic notes, outlines, diagrams, flow charts and even mind maps, but there are also standardised ones such as mathematical and scientific notations.

Making an external representation for a group process requires both a carrier of the external representation, such as pen and paper or a software tool, and a formalism, such as a common language or representational technique, to guide knowledge externalisation (Suthers 2001). This formalism is thus a set of objects and rules that guides making an external representation.

Causal mapping (Bryson et al. 2004) is a good example of a specific formalism. Bryson et al. define it as "a word-and-arrow diagram in which ideas and actions are causally linked with one another through the use of arrows. The arrows indicate how one idea or action leads to another." In other words, the formalism objects are the ideas or actions represented by the words in the diagram, and the formalism rule for making the cause map is that the arrows to link the ideas and actions must indicate causes and consequences. gIBIS (graphical IssueBased Information System; Conklin and Begeman 1987), another example of a specific formalism, supports team design deliberation. It requires the user to distinguish between issues, positions, and arguments (nodes) and their interrelations, using prespecified link types (e.g., generalises, specialises, questions, supports). In gIBIS, the node and link types are the formalism objects. Furthermore, gIBIS uses a set of rules ("legal rhetorical moves;" Conklin and Begeman, p. 248) that describes which types of links may legally be used to connect the nodes.

Many different formalisms exist, because they can be tailored to specific activities. Suthers (2001), for example, developed a formalism to enhance scientific discourse, which he implemented in a software tool called Belvédère ${ }^{\circledR}$. This formalism consists of a small set of rules which (1) require evidence for every statement made by the group, (2) require opposing evidence for each group statement, and (3) prompt users to check whether the evidence supports statements other than the one it was given for. This formalism helps teams to distinguish between strong and weak statements, and to articulate uncertainties.

A formalism can influence both knowledge externalisation and knowledge internalisation (Figure 2). It can facilitate problem solving processes if it limits the problem space without excluding information and relevant knowledge. An associated risk is using an inadequate formalism. Consider the problem of using the Belvédère ${ }^{\circledR}$ formalism, with its empirical 


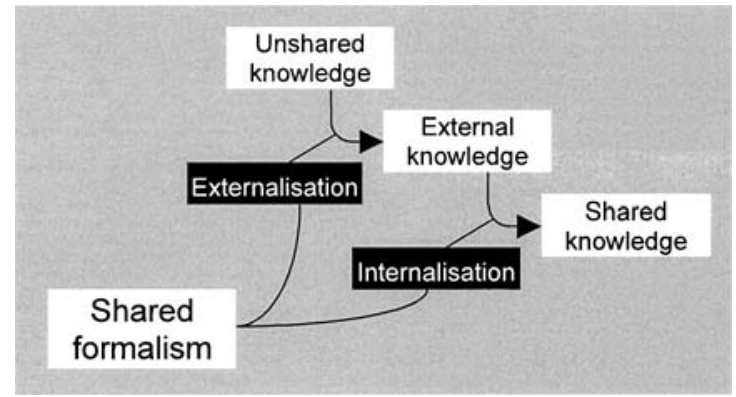

Figure 2. Formalisms focus knowledge externalisation and knowledge internalisation.

scientific discourse-orientation, in fields such as law or design (cf. Verschuren 1997). Using such an out-of-context formalism can be a hindrance at best, and counter-productive at worst (Van Bruggen 2003). In such cases the ontology of the formalism does not fit, or even conflicts, with the ontology of the problem domain. A formalism needs to fit the activity it attempts to facilitate.

\section{A Formalism Based on Negotiation Primitives}

Negotiation, as previously stated, can be broken down into a small number of primitives. The primitives can be seen as objects that result from actions by team members. A formalism that aims to facilitate negotiation has to support these actions. In regular communication, the status of people's statements in terms of negotiation primitives remains implicit. Using a formalism designed to facilitate negotiation has to enable distinguishing between original contributions, clarifications, verifications, et cetera, and make the steps in negotiation explicit. By doing so, differences in understanding and opinion should more easily surface. Table 1 presents the formalism. Rule 2 and 3 of the formalism can be iterated until common understanding of the contribution is reached (cf. the grounding criterion). Rule 4, about Acceptance/Rejection, shows the importance of clarification and verification. For example, the statement $1+1=10$, for example, is true only if we understand (through rules 1 and 2) that the contributor is using the binary system. In the case of irresolvable disagreement about previously accepted statements, the fifth rule may result in multiple scenarios, each based on another value judgement (i.e., agree to disagree).

Using the formalism is expected to induce more negotiation of meaning and negotiation of position, because encouraging people to make their private understandings and opinions public will make differences in understanding and opinion visible or salient (Bromme 2000). This will be reflected in negotiation by the number of verifications and clarifications for every original contribution. By strengthening the negotiation process, we thus expect this formalism to increase the amount of common ground. 
BEERS ET AL.

Table 1. Rules for a formalism for the facilitation of negotiation.

1. Every new issue is termed a contribution

Contributions are assumed not to be part of a team's common ground

2. Contributions require a verification by the other team members

Every team member must verify whether their understanding of the contribution

sufficiently matches what the contributor intended, in order to assist in the

detection of differences between individual representations

3. Each verification is responded to with clarification

The original contributor has to explicitly clarify what she/he intended, in order to overcome differences between individual representations

4. When all verifications are clarified, and no new verifications are performed, all team members state whether they accept or reject the statement

Acceptance or rejection of a contribution is based on one's judgement of whether it is right. A contribution should be accepted as part of the common ground if all accept it as true, or after it has been modified to become accepted

5. All team members are required to state their position about accepted statements People are required to state their positions to allow for clarification/ determination of perspective, which in turn aids in the verification and clarification of further contributions

Study

A pen-and-paper version of the formalism for supporting negotiation was tested in which team members were requested to both state their position concerning others' contributions in a face-to-face setting, and to explicitly verify and clarify their contributions on a flip-over against idiosyncratic representation and negotiation. The study was as much a test of the formalism as it was a test of how to create the proper research setting, and a test of analysis methods to determine:

1. whether the formalism influences negotiation of common ground;

2. how participants experience negotiation and achieving common ground; and

3. how participants used the formalism.

The formalism was expected to make negotiation more explicit. Furthermore, groups using the formalism were expected to negotiate each contribution more thoroughly than groups without the formalism. Finally, the formalism groups were expected to establish more common ground than the non-formalism groups, caused by the increased negotiation. Common ground was operationalised as overlap between individual representations. 
The second aspect focusses on the validity of the research setting. Interview data were used to draw in-depth impressions of two topics in particular, namely participants' thoughts about multiple perspectives and negotiation, and their awareness of grounding and perspectives during collaboration. The data were used to test whether the present research setting corresponded sufficiently to a complex problem solving situation, as perceived by the participants, to test the uses of the formalism. Furthermore, it was intended for gaining insight into whether participants were aware of the presence of multiple perspectives and the need for actively achieving and maintaining common ground.

The third aspect focusses on how participants actually used the formalism, and what they used it for.

\section{Method}

Six groups (triads) of senior college students who were given a problem-solving task were studied. They were instructed to collaboratively carry out this task. Half of the groups were instructed to use the formalism for working with a white- or blackboard and flip-over to structure their collaboration (the formalism condition). The other groups could use these materials any way they wanted to (the idiosyncratic condition). Afterwards, all participants were interviewed.

\section{Participants}

Participants were students in their senior year from a business degree program of a Dutch University. Participants majored in such fields as Accountancy, Marketing, Organisation Science, and Macro-economics. Six teams were formed by dividing participants who majored in different fields into groups of three. Note that senior college students will behave differently from real management teams in some respects, because they don't have a shared history, and probably will not have a future together that needs to be reckoned with during collaboration (Eden 1995).

\section{Materials}

Task.

A task was assigned to the groups, requiring them to arrive at an investment decision for a machine-producing company called "Thyssen and Krupp". The assignment was derived from the (computer) simulation game "STEER The Economy" (Woltjer 2003). Participants were provided with a large amount of company and market data covering such diverse fields as the company itself and its past decisions, competing companies, within-market developments, and overall macro-economic indicators. The abundance and variety of available data 
enabled complementary approaches from multiple business perspectives. The participants received the following task description:

You are employed as an organisational consultant to analyse and advise organisations. Thyssen and Krupp, a company which produces machines, contracts you to advise them on an investment decision. They require an analysis of their current situation and an investment strategy for the near future (number and type of machines ordered). All data regarding Thyssen and Krupp are available on your computer.

\section{Formalism.}

Participants were supplied with a blackboard or whiteboard (henceforth 'board') and flipover, and writing materials of different colours. Groups that used the formalisms received the instruction to use the board and flip-over as much as possible during discussion for writing down new topics for discussion, and for sharing opinions about those topics. Each participant used a specific colour for writing his/her contributions.

The flip-over was to be used for clarification of contributions. Participants were to represent their own understanding of others' contributions on the flip-over. The original contributor could subsequently, also on the flip-over, represent what s/he really meant. This means that participants were not meant to discuss each other's opinions on the flip-over.

Once sure of understanding a contribution, participants could represent this on the board by initialling the original contribution. Finally, participants could represent their opinions about each other's ideas on the board, and also use the board to represent new ideas from the discussion.

In sum, the board was intended for recording ideas and opinions and the flip-over was intended as a means to clarify the understanding of those ideas. Participants were instructed to begin with a short brainstorm on the board, and then continue on the flip-over with clarifications. After completing those two steps, the course of discussion was free. The groups that did not use the formalism could use the board and flip-over to their own discretion. These groups are referred to as the idiosyncratic groups.

\section{Interview guideline}

Participants were individually interviewed to gain insight in their thoughts about perspectives and negotiation, as well as their awareness of grounding and perspectives during collaboration. The interviews were conducted by three graduate assistants who had received training in basic conversational and interview techniques as part of their university education. Each interviewer conducted six individual interviews. The interviews focussed on how the participants arrived at new ideas; how new ideas were introduced and exchanged during collaboration; whether ideas "landed" by the other team members; whether team members understood each other; and whether team members agreed with each other. 


\section{Procedure}

Participants were given 45 minutes to explore the simulation and browse through all the different types of graphs and charts to get some experience with the information available in the program.

After this exploration, participants started working on the case. In order to promote the construction of an individual perspective, as well as to allow the researchers to determine participants' individual representations, participants first carried out the task individually (pre-test) and wrote down their solutions.

Next, participants had to collaboratively carry out the task in triads. They received a board and a flip-over to take notes. Half of the groups received the formalism instruction and the other half could use the materials in an idiosyncratic way. All groups were instructed to use the flip-over for writing down their final solution to the problem task. Participants were allowed to bring their notes. The collaboration process was videotaped.

After the collaboration, participants were again asked to individually carry out the task (post-test).

The interviews were conducted as soon as possible after collaboration (always within 24 hours). All interviews were tape recorded and typed out by the interviewer who conducted them. Video recordings of the collaboration process were used during the interview to stimulate the participant's recall of their thoughts during collaboration. The participants watched the video-taped collaboration process and were instructed to report the thoughts they had had during collaboration. They were instructed to pause the video recording at any time if they wanted to report their thoughts. The interviewers could also pause the video recording during the interview if they wanted to ask the participants to report their thoughts, and were instructed to do so when the participant was silent for an extended period, had reacted fiercely to another on the video tape, and vice versa, had spent an extended period searching for information or was neglected by the others. Figure 3 schematically represents the procedure for one triad.

\section{Variables and Analysis}

Negotiation, common ground, and participants' thoughts about negotiation of common ground were analysed. Negotiation was operationalised as quality of negotiation; negotiation per conversation topic; and participation per conversation topic during the collaboration. Common ground was measured by comparing individual representations before and after collaboration with respect to solutions and their justification. Thoughts about negotiation were measured by qualitative analysis of the interview data.

\section{Quality of negotiation}

We developed a coding scheme for coding function and content of utterances during collaboration (cf., e.g. Thomas et al. 1982; Fischer et al. 2002; Mulder et al. 2002). All utterances 
BEERS ET AL.

were coded with regard to:

- Cognitive content: Utterances directly related to solving the problem.

- Regulative content: Utterances related to monitoring the problem solving process, and regulating the collaboration process. Talk about the formalism instruction was coded Regulation as well.

- Other content: Any utterance not in another category, or non-codable.

Utterances with cognitive content were specifically coded for function, using subcategories based mainly on the primitives, namely:

- Contribution: An utterance in which a new topic of conversation not discussed before is introduced.

- Elaboration: An utterance in which a contribution is expanded upon by either adding more information, agreeing, disagreeing, accepting, rejecting or summarising.

- Verification: An utterance in which, directly or indirectly, information is requested about the intended meaning of a contribution or elaboration.

- Clarification: An utterance in reaction to a verification or a perceived lack of understanding, in which the intended meaning of a contribution or elaboration is elucidated.

The coding scheme originally included separate categories for acceptance, rejection, agreement, and disagreement. However, very strict coding rules were needed to make these categories reliable, and with these rules the number of instances of the respective utterances was too small to be incorporated in the analyses.

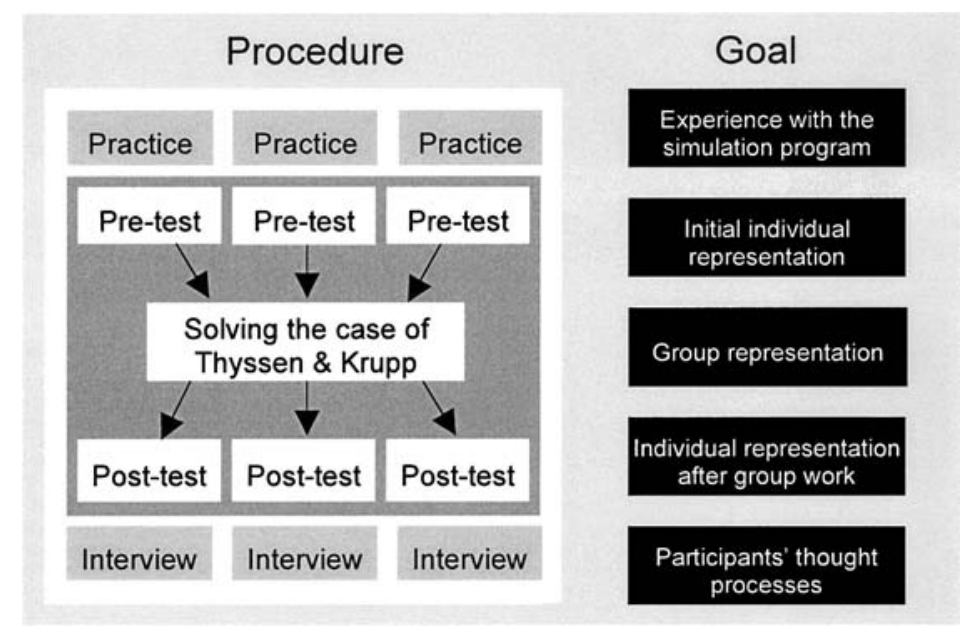

Figure 3. Experimental design. 
Segmentation was done on the basis of utterances. However, acknowledgements (e.g., "Hmhmm," "yeah, yeah," etcetera) were ignored. Furthermore, if a speaker obviously changed the type of utterance in mid-speech, it was split into two segments. Segmentation and coding were done simultaneously.

A graduate assistant was trained for 25 hours on the use of the coding scheme and the video-coding software package The Observer ${ }^{\circledR}$ (Noldus et al. 2000). Comparable data from an experiment without the formalism with second-year students were used for training purposes. Comparing a sample of 25 minutes of video-data $(9 \%$ of the total amount of videodata) coded by the first author and the graduate assistant resulted in a substantial (Landis and Koch 1977) inter-rater reliability (Cohen's kappa) of .68 (SE = .066). All data were coded by the graduate assistant, blind to which trials corresponded to which condition.

Verification and clarification were seen as indicative for explicit negotiation activities. The total number of contributions discussed was used as an indicator for the range of topics discussed. It was assumed that the wider the range of discussed topics, the better different perspectives were represented.

\section{Negotiation per conversation topic}

To measure the number of verifications and clarifications per conversation topic first those episodes in the discussion that dealt with one conversation topic were identified. The contributions that were identified earlier using the coding scheme served as a means to identify these episodes. A discussion episode generally started with a contribution, and ended when one of the participants would make a new contribution, and all the intermediate discussion between these contributions would deal with one conversation topic.

Note that in specific cases the discussion about one topic was interspersed with discussion of another, for example when the focus of discussion would go back and forth between topics. In such cases all discussion about one topic would be added to one episode, even when it was interspersed with another episode. Negotiation per conversation topic was operationalised as the total number of verifications and clarifications per episode.

\section{Participation per conversation topic}

The participation per conversation topic was operationalised as the number of participants that made an utterance or an acknowledgement during an episode. Effectively this means that participation can be 1 (in case of a monologue to which no one reacts), 2, or 3 for each conversation topic, depending on the number of speakers during the corresponding episode. 
BEERS ET AL.

\section{Common ground}

A large body of research on the measurement of variables such as common ground (e.g. shared knowledge, group mental model) exists (e.g., Bougon 1992; Langfield-Smith and Wirth 1992; Bood 1998), which all involve some form of cognitive mapping. A cognitive map is a representation of an individual's or a group's beliefs. Cognitive maps can be drawn based on data like discussion transcripts, interviews, texts, etcetera. Subsequently, techniques like content analysis can be used to code the content of the data. Finally, individual cognitive maps can be combined to represent knowledge of a group (Bougon 1992). We used content analysis as a technique to map the individual problem representations. Common ground was conceptualised as the extent to which individual representations overlapped each other with regard to content.

To characterise the content of the individual representations the group discussion content itself was first characterised (see Figure 4). The discussion episodes identified earlier served as a basis for characterising the discussion content. Each episode was first numbered and labelled with a descriptive summary. For example, one of the episodes was summarised as follows: "The current low stock of Thyssen and Krupp is only a random indication because stock is fluctuating within the nine-month time of delivery for new machines."

The next step involved characterising the content of the individual representations, both prior to (pre-test) and subsequent to collaboration (post-test), as well as characterising the content of the group representation. For every individual representation the topics represented and not represented were assessed. In Figure 4, episode number 7 is judged to be present in one of the initial individual representations (Jane's) in the group representation, and in all of the post-tests. By repeating this procedure for each of the episodes in the discussion, it was determined where each conversation originated, whether it was present in the group representation, and whether participants used it in their posttests.

Three different measures of common ground were used, based on different comparisons of individual and/or group representations. The first measure concerned the overlap of individual representations subsequent to collaboration (overlap after collaboration). The second measure concerned the difference between overlaps of pre-tests as compared to post-tests (change in overlap). The third measure constituted a comparison of the overlap of the post-tests to the group representation.

\section{Qualitative Analysis of the Interview Data}

The interviews were qualitatively analysed to gain insight in the participants' thoughts about multiple perspectives and negotiation, and their awareness of both grounding and multiple perspectives during collaboration. These topics are important to help judge the validity of the research setting, that is, whether there was enough initial misunderstanding between participants to sufficiently allow for negotiation processes, and whether the participants were able to learn from each other through negotiation (i.e., that different perspectives added value to solving the problem). It is also important to explore whether the participants were aware that different perspectives apply to the task, and that there is a need for achieving 


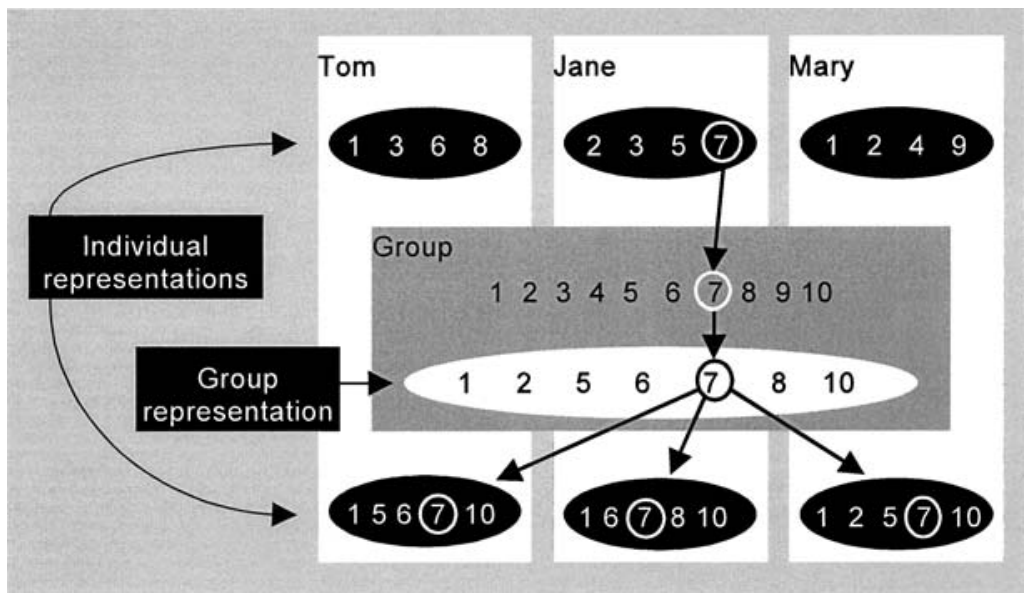

Figure 4. Analysis of common ground; numbers indicate topics.

and maintaining common ground. The qualitative analysis was also used to gain insight in participants' use of the formalism, by focusing on the way the participants used the board and flip-over.

To address these questions, all reported thoughts from the interview transcripts about any of the aforementioned aspects of negotiation were gathered and categorised. To assess differences between formalism and idiosyncratic groups it was determined whether some thoughts occurred only in the formalism groups and not in the idiosyncratic groups for each topic, and vice versa.

The qualitative analysis was carried out by the first author.

\section{Results}

\section{Quality of negotiation}

Table 2 shows the mean number of occurrences for each of the primitives for both the formalism and the idiosyncratic groups. Formalism groups worked longer than idiosyncratic groups. During that time, they discussed more contributions, and each of these contributions was negotiated more thoroughly, as shown by the amount of negotiation of meaning per contribution, than in the idiosyncratic groups. In general, the number of verifications and clarifications was higher in the formalism groups than in the idiosyncratic groups. MannWhitney testing showed that the difference in number of clarifications was marginally significant, $U(N=6)=.500, p=.072$. Furthermore, in the formalism groups the mean number of participants per conversation episode was significantly higher than in the idiosyncratic groups, $\chi^{2}(2, N=150)=8.77, p<.05$. No other differences were found to be statistically significant, although all of the observed differences were sizeable and in the expected direction only. Seeing as how the sample was small and the research was explorative 
BEERS ET AL.

Table 2. Negotiation primitives.

\begin{tabular}{|c|c|c|c|c|}
\hline & \multicolumn{2}{|c|}{ Formalism groups } & \multicolumn{2}{|c|}{ Idiosyncratic groups } \\
\hline & $M$ & $S D$ & $M$ & $S D$ \\
\hline Group time on task (in seconds) & 3181 & 394 & 2341 & 579 \\
\hline Contribution $^{\mathrm{a}}$ & 27.0 & 7.8 & 23.0 & 4.4 \\
\hline Verification $^{\mathrm{a}}$ & 17.0 & 5.2 & 10.7 & 3.5 \\
\hline Clarification $^{\mathrm{a}, \#}$ & 23.3 & 7.5 & 14.7 & 1.2 \\
\hline Negotiation of meaning ${ }^{\mathrm{a}}$ & 40.3 & 12.2 & 25.3 & 2.5 \\
\hline Elaboration $^{\mathrm{a}}$ & 197.3 & 57.6 & 151.7 & 18.8 \\
\hline Regulation $^{\mathrm{a}}$ & 30.0 & 6.6 & 24.0 & 13.1 \\
\hline Other $^{\mathrm{a}}$ & 43.0 & 14.2 & 32.7 & 21.2 \\
\hline Negotiation ${ }^{\mathrm{b}}$ per contribution & 1.7 & 1.0 & 1.1 & 0.1 \\
\hline Participants per episode* & 2.8 & 0.22 & 2.5 & 0.09 \\
\hline
\end{tabular}

${ }^{a}$ The unit for this variable is the utterance. For example, with regard to Contribution, this means that in the formalism groups on average 27 utterances were coded Contribution.

${ }^{\mathrm{b}}$ Negotiation is meant here as negotiation of meaning, and consists of the sum of all verifications and clarifications.

${ }^{\#} p<.10 ;^{*} p<.05$.

in nature, this was not unexpected. On the whole, the data suggest that the formalism groups negotiated longer, more and more thoroughly than the idiosyncratic groups.

\section{Common ground}

Table 3 shows that the participants in the formalism group discussed more topics than the participants in the idiosyncratic group. Also, the members of the formalism groups mentioned

Table 3. Common ground.

\begin{tabular}{lrllll}
\hline & \multicolumn{2}{c}{ Formalism groups } & \multicolumn{2}{c}{ Idiosyncratic groups } \\
\cline { 2 - 3 } \cline { 5 - 6 } & \multicolumn{1}{c}{$S$} & $S D$ & & $M$ & \multicolumn{2}{c}{$S D$} \\
\hline Total number of episodes & 27.0 & 7.8 & & 23.0 & 4.4 \\
In one pre-test & 12.0 & 3.6 & & 11.7 & 2.9 \\
In two pre-tests & 2.7 & 1.5 & & 2.7 & 2.9 \\
In three pre-tests & 1.0 & 1.0 & & .3 & .6 \\
External representation & 10.7 & 2.3 & & 13.0 & 7.8 \\
Solution & 6.3 & 5.1 & & 4.0 & 1.7 \\
In one post-test & 7.3 & 3.1 & & 6.3 & 1.2 \\
In two post-tests & 4.3 & 2.1 & & 4.7 & 1.5 \\
In three post-tests & 2.0 & 1.7 & & 2.0 & 1.7 \\
\hline
\end{tabular}


more different discussion topics in their post-test problem representations. However, the idiosyncratic groups captured more discussion topics on their group external representation than the formalism groups $(M=13.0$ vs. $M=10.7)$ as can be seen in Table 3 . Furthermore, the number of discussion topics mentioned in the post-tests (overlap after collaboration) by all members is the same for both conditions $(M=2.0$, number of discussion topics in three individual representations), which means that no difference in common ground was found. Adding pre-tests to the measurement of common ground (measuring change in overlap) suggests a bit more common ground in the idiosyncratic groups.

When comparing the overlap between post-tests to what was in the external representation, the idiosyncratic groups, although they captured more topics on their external representation, did not subsequently show more overlap between individual posttests.

It may be the case that the present analysis method was too crude to make the differences between the groups visible. For example, one person in one of the idiosyncratic groups decided to externally represent all her contributions, which heavily coloured the results. This practice also indicates that social loafing (Latané, Williams and Harkins 1979) may have influenced the outcome measure for common ground. One of the formalism groups, on the other hand, decided to not write anything down before all agreeing upon it. Although this meant acting in the spirit of the formalism, it led to an under-representation of contributions on the board.

\section{Participants' Thoughts, Perspectives and Negotiation}

The qualitative analysis yielded observations about multiple perspectives and negotiation and participants' awareness of grounding and perspectives. Interview excerpts are provided to give the reader an impression of the data that informed our observations.

\section{Multiple perspectives and negotiation}

In the interview data, the presence of multiple perspectives is apparent through frequent misunderstandings among participants and through the experience of benefiting from each others' contributions in solving the task.

The interview data indicate that at a number of moments participants detected a misunderstanding on the part of one of their discussion partners. Sometimes they felt they were justified in this judgement, for example, when it was plain from discussions that one of the discussion partners was not able to follow the discussion at all. At other times though, participants merely assumed that one of their discussion partners was incorrect. In some of these cases these participants had no intention of questioning their own views, even if it later became apparent that they themselves were 'wrong' and their discussion partners 'right': 
BEERS ET AL.

"Cause she said much, but half of it wasn't relevant."
"If you ask me, the one on the left, I think she just lost it."
"But at that point I thought, no, that's really a stupid remark. And later on he even convinces me, if I recall correctly.
But at that point I immediately think, no, that's stupid."

At times, participants would sense a major misunderstanding between them and their discussion partners without trying to repair this misunderstanding:

"This is really bad of me. Cause I nod while I haven't heard a word of what she said."

In the above misunderstandings, there was no attempt to repair them, based upon the interview data. Participants seemed to be content with their own, or their partners', lack of understanding for the purpose of solving the case. Such misunderstandings, without ambition to overcome them, were observed in both the idiosyncratic and the formalism groups. The data suggest that the formalism does not support negotiation in cases where participants are not at all interested in trying to understand each other.

Despite the misunderstandings mentioned above, participants also reported that they had the opportunity to learn from each other during the problem solving process:

"I enjoyed seeing how you can build on one another until you reach a good answer."

From the interview data it seems that participants felt they were able to achieve a better result collaboratively than they would have by themselves, because they gathered knowledge and insights from their discussion partners and in some cases collaboratively constructed the meaning of some piece of data in the computer system.

"At this point I'm finding out that through discussions you can gain far more insight in what's happening."

Participants in both the formalism and the idiosyncratic groups reported that they were able to profit from each other.

The above observations indicate that the research setting, i.e., a higher education problem solving situation, in principle offered enough opportunity for negotiation activities, if misunderstandings become explicit and there is commitment to address them. The setting appeared to allow for collaborative negotiation of meaning and knowledge construction, as the participants reported being able to benefit from each other's knowledge. From these observations it is apparent that the setting under study allows for studying the framework.

\section{Participants' awareness of grounding and perspectives}

Participants' awareness of grounding is apparent from the interview data in two ways. First, various interview excerpts show that participants consciously account for each others' business expertises. Second, there are several instances in which participants consciously 


\section{COMMON GROUND AND DECISION MAKING}

clarify and verify their understanding, in various degrees of commitment to achieving and maintaining common ground.

From the interviews it seems that participants deemed the differences in background between them and their partners relevant to the topic at hand:

"But I had heard that she had done Econometrics, was currently doing Economics, so she's probably looking at totally different things than we are."

"I don't know what they majored in, but I think they know more about company management than I do."

On the other hand, sometimes perspectives were seen as a cause of ignorance:

"I also thought, he's studying Econometrics, so maybe he doesn't really get the picture."

In both idiosyncratic and formalism groups, participants were aware of such differences in perspective.

In sum, it appeared that the participants linked the perspective of their discussion partners to differences in problem representations, and that they thought that these different perspectives might add new points of view to the discussions. Both acknowledging the difference between understanding and agreement and acknowledging differences in perspective can be seen as a prerequisite for effectively using the formalism, because the rules of the formalism imply a certain awareness of these differences.

The interview data also suggested various, qualitatively different ways in which participants reported activities related to grounding. Three ways in which participants attended to their team partners' contributions were observed. First, they actively tried to increase participation of the discussion partners, especially in the case of someone who was very quiet:

"I wanted to hear what she had to say. Because she had been quiet for some time already."

"So I let him finish, that speaks for itself, that you hear what someone's got to say."

A second example of grounding was being actively open to feedback from discussion partners, and being able to accept it. In various cases participants made contributions that their discussion partners deemed false. In such cases, being open to arguments against one's own position is seen as being open to clarifications from other team members:

"So maybe [I didn't make] the best suggestion, but the feedback was very good. Both [team partners] gave me a reason why you could see it differently."

"I liked that. ... they explained to me how I arrived at a wrong interpretation."

The third way takes commitment to grounding one step further. There were specific cases where participants reported an active effort to achieve common ground in cases of misunderstanding on the part of one of their discussion partners, even when this discussion partner did not actively request any further explanation or clarification and could have been easily ignored:

"And it's probably from his eyes that I could tell, or his way of, I don't know, his behaviour at that moment, and that's why I thought, I have to ask if he understands it. Because at that moment I'm like, he doesn't get it." 
"I tried to explain it to him in such a way that he might understand it as well." "We found a conclusion of which I found that it was one hundred percent of what the three of us thought ... . . What I found most important, was that we had a conclusion we all could support [rather] than a conclusion that was one hundred percent correct, but to which one of us did not agree."

In conclusion, despite often misunderstanding each other, or having disagreements, participants also actively tried to establish common ground. This was apparent in attempts to involve silent team members in the discussion, in being open to feedback from others, and in actively trying to repair misunderstandings. This last type of commitment to grounding was only observed in the formalism groups. The other types grounding were observed in both formalism and idiosyncratic groups.

\section{Use of the Formalism}

In the interviews, the participants mentioned various uses of the board. The most important use seems to be that it acts as a record for points that everyone agrees upon. When something is written down on the board, it seems to get the status of common ground. This was the case for both the formalism groups and the idiosyncratic groups:

"I didn't really agree with what he said. You can tell, 'cause I didn’t write it down."

In some cases participants attributed a certain status to a point of discussion if it was written on the board:

"So just confirming officially by writing it on the board."

The board also was reported to help structure the discussion. Participants saw the use of the board as a mechanism to keep track of the various topics that had been discussed, and sometimes used it as a structuring tool by using specific space on the board for a specific part of the case (for example, the left side of the board for market analysis, and the right side for company analysis):

"And I thought if we don't write that down we're gonna lose structure, so."

Furthermore, in some cases participants who brought little to the discussion judged that they could make themselves useful by writing things down on the board. From the interview data it is also clear that this was seen as useful by the discussion partners:

"Then I'll start writing on the board. That way I can do something useful as well."

The board thus appeared to serve as a lasting record for knowledge that was part of common ground, as a means to structure the discussion, and even as an excuse for having relatively little to contribute in terms of content. Participants did not, however, report thoughts in which they linked use of the board to the formalism. 


\section{Conclusion and Discussion}

This article introduces a framework for decision support of multidisciplinary teams, and an exploratory study to test its method.

With regard to negotiation, results indicate that the formalism groups spent more time on negotiation processes than those not given the formalism (i.e., who used their own idiosyncratic representation method). Furthermore, members of the formalism groups participated in more of the discussion topics than those in the idiosyncratic groups. This, and the fact that the formalism groups discussed more conversation topics than the idiosyncratic groups, suggests a more equal representation of different perspectives in the collaboration process than in the idiosyncratic group. Difficulties in following the formalism might be an alternative explanation for the difference in total time on task. However, such difficulties are not represented in the number of contributions, verifications, clarifications or elaborations, since talk about the formalism was coded as regulation. With regard to common ground, the results did not indicate any differences or trends between the groups. This may be due to the crudeness of the common ground-measure used here. Also, possible confounding factors like social loafing have not been taken into account. If the formalism did positively influence the extent of common ground, it was not apparent in the results.

Other researchers have also developed formalised discussion techniques to facilitate decision making, e.g., the Nominal Group Technique (Van de Ven and Delbecq 1974) and the Delphi technique (Rowe and Wright 1999). These techniques are similar to the formalism tested here in that they both have separate phases for evaluation and clarification of ideas, but they differ in that they close off with rounds of voting, which effectively removes the possibility of agreeing to disagree. Van de Ven and Delbecq found that both Delphi and the Nominal Group Technique increased the number of contributions as compared to groups without a specific formalism, just as our results with the negotiation formalism. Also, participants in their studies opined that they had little time to think each other's ideas through, whereas participants using Delphi or Nominal Group Techniques interacting groups reported having ample opportunity to do so. These results are like ours; the formalism increased negotiation activities, which indicates that participants considered others' ideas more than in idiosyncratic groups.

With respect to the first research question, namely whether the formalism influences the way negotiations take place, the results lend credence to the hypothesis that the formalism is able to make negotiation more explicit, and so facilitate the negotiation of common ground.

The interview data shed some light on participants' experiences of negotiation of common ground. Participants report that they can benefit from each other's knowledge throughout solving the case, and appear to consciously take action to repair detected misunderstandings on the part of their discussion partners. According to Ostwald (1996) this is an important aspect of the grounding process; repairing a breakdown in understanding results in an increase in common ground. Furthermore, participants showed active commitment to negotiating and maintaining common ground, through consciously paying attention to each other and shaping their clarifications to the perspective of their team members. The results suggested that commitment to grounding was exercised most actively in the formalism 
groups. However, as the study was of an exploratory nature more research is needed to allow for firmer conclusions.

From the interviews it was clear that the board served a variety of purposes during the collaboration. It did not become clear whether the participants were aware of the formalism as intended in this specific setting. Nonetheless, participants did discuss their formalism instructions during work. for example when they were deciding whether to use the board or the flip-over to record their ideas. From a methodological perspective, these results indicate that laboratory setting studied here offered enough opportunities for grounding processes to take place. It can be concluded that the present research setting acted as a valid model of multidisciplinary problem-solving for studying the framework.

The present study excluded possible learning effects, because it only offered the participants one attempt at using the formalism. With repeated attempts, participants conceivably might become more adept at recognising differences in representation, and more experienced in using verifications and clarifications to repair misunderstandings. This raises the question whether participants can learn the rules of the formalism and ultimately apply them without the instruction to use the formalism. Also, it alludes to the possibility that participants identify unintended uses of the formalism that have not been described here (cf. Nunamaker et al. 1991), which indicates an appropriation of the formalism.

There were some cases where participants were conscious of misunderstanding and did not repair it. This finding requires discussion because it may have implications for the effects of the formalism in a practical setting. Some aspects of "presentation of self" (Goffman 1959) may play a part here. Participants may have been more interested in conveying the message of understanding the others, of being on common ground, than to convey a message of mutual difference, as would be clear when misunderstandings would have been made explicit. They would face a trade-off between their presentation of self and repairing a misunderstanding, where making a misunderstanding explicit is not in the best interests of presenting an "optimal" self.

The question is what the implications of this result are for the effectiveness of the formalism in a professional situation with large interests at stake. For example, what will managers do when they are confronted with colleagues who hold views they deem incorrect/misunderstood? If the colleague is perceived as a competitor, the manager might wait and hope for a mistake without ever making the misunderstanding explicit. If however, such a mistake would reflect on the manager's esteem, she/he might try to persuade the colleague to his/her own view, even so much as to not be open at all to the colleague's clarifications. The point here is that in professional situations, a number of strategic considerations absent from the laboratory setting may play a role that might influence the extent to which discussion partners are willing to make their private understandings and positions public. More research is needed to gain insight in negotiation processes in the presence of such strategic considerations.

In the present study, a pen-and-paper implementation of the formalism was used. This appeared to have certain drawbacks compared to an ICT-implementation (Beers et al. 2005). For example, one can only hope, and cannot enforce, that participants sufficiently follow 
instructions, and make use of all the materials that are part of these instructions. Furthermore, little can be done about participants unwilling to follow the instructions. Had an ICTimplementation of the formalism been used, participants could have been "forced" into certain activities to make them adhere more closely to the formalism. Further research is needed to decisively test this. In future studies, scripting methods in ICT-tools, can "force" or "coerce" participants to adhere to the formalism more closely.

At present a number of ICT-tools for group support exists (e.g., Belvédère ${ }^{\circledR}$, Suthers 2001; gIBIS, Conklin and Begeman 1987). The formalism presented here is rooted in theory about negotiation of common ground, a specific discussion type. In that sense it is similar to Group Systems (Nunamaker et al. 1991). Group Systems is an electronic meeting system that consists of a toolkit aimed at things like group memory, group interaction, and session management. For example, it has a specific tool to facilitate the process of brainstorming. With Group Systems, a team uses a series of different tools selected for the purpose of the group meeting, with each tool supporting a specific meeting activity. One way to implement the formalism could be as a Group Systems tool to be used in case negotiation of common ground is particularly important. As such it could support Group Systems activities like exploration and idea generation (Nunamaker et al.); the formalism could aid idea exploration through the explication of individual representation, and subsequently affording the negotiation of common ground. As such, the formalism would structure part of the group process.

Eden (1992) writes about the importance of negotiation processes for Group Decision Support Systems in general. On the one hand, Eden emphasises the importance of maintaining social order when using group decision support systems, while on the other hand enough diversity needs to remain to prevent phenomena like "group think." According to Eden, a way around this problem is to increase participants' commitment by letting them experience their problem from the other's perspective. Our results show that the formalism presented here might facilitate this process. The implications of our results for group decision support systems then are that paying attention to the negotiation of common ground by having participants verify their understanding, and them explicate their positions could increase the effectiveness of group decision support systems.

\section{Acknowledgement}

We would like to thank Marjolein van Asselt, our colleagues at OTEC, and our team members in Maastricht, Mien Segers, Piet Van den Bossche and Emily Teunissen for their input and ideas. This research was funded by the Dutch National Organisation for Scientific Research (NWO).

\section{References}

Alpay, L., A. Giboin, and R. Dieng. (1998). "Accidentology: An Example of Problem Solving by Multiple Agents With Multiple Representations," in M. W. Van Someren, P. Reimann, H. P. A. Boshuizen and T.De Jong (eds.), Learning with multiple representations. Oxford. UK: Elsevier, 152-174. 
Baker, M. J., T. Hansen, R. Joiner, and D. Traum. (1999). "The Role of Grounding in Collaborative Learning Tasks," in P. Dillenbourg, (Ed.), Collaborative learning: Cognitive and computational approaches. Amsterdam, The Netherlands: Pergamon/Elsevier Science, 31-63.

Bechky, B. A. (2003). "Sharing Meaning Across Occupational Communities: The Transformation of Understanding on a Production Floor," Organization Science 14, 312-330.

Beers, P. J., P. A. Kirschner, H. P. A. Boshuizen, and W. Gijselaers. (2005). "Computer Support for Knowledge Construction in Collaborative Learning Environments," Computers in Human Behavior 21, 623-643.

Bood, R. P. (1998). "Charting Organizational Learning: A Comparison of Multiple Mapping Techniques," in Eden, C. and J.-C. Spender, (Eds.), Managerial and organizational cognition. London, UK: Sage Publications, 210-230.

Boshuizen, H. P. A. and J. M. Tabachneck-Schijf. (1998). "Problem Solving With Multiple Representations by Multiple and Single Agents: An Analysis of the Issues Involved," in M. W. Van Someren, P. Reimann, H. P. A. Boshuizen and T. De Jong, (Eds.), Learning With Multiple Representations. Oxford, UK: Elsevier, 137151.

Bromme, R. (2000). "Beyond One's Own Perspective: The Psychology of Cognitive Interdisciplinarity," in P. Weingart, and N. Stehr, (Eds.), Practicing Interdisciplinarity. Toronto, Canada: University of Toronto Press, 115-133.

Bromme, R. and M. Nückles. (1998). "Perspective-Taking Between Medical Doctors and Nurses: A Study on Multiple Representations of Different Experts With Common Tasks," in M. W. Van Someren, P. Reimann, H. P. A., Boshuizen and De Jong, T. (eds.), Learning With Multiple Representations. Oxford, UK: Elsevier, 175-196.

Bromme, R., R. Rambow, and M. Nückles. (2001). "Expertise and Estimating What Other People Know: The Influence of Professional Experience and Type of Knowledge," Journal of Experimental Psychology: Applied $7,317-330$

Bryson, J. N., F. Ackermann, C. Eden, and C. B. Finn. (2004) Visible Thinking: Unlocking Causal Mapping for Practical Business Results. Chichester, UK: John Wiley and Sons.

Bougon, M. G. (1992). "Congregate Cognitive Maps: A Unified Dynamic Theory of Organization and Strategy," Journal of Management Studies 29, 369-389.

Clark, H. H. and S. E. Brennan. (1991). "Grounding in Communication," in L. B. Resnick, J. M. Levine and S. D. Teasley, (Eds.), Perspectives on Socially Shared Cognition. Washington DC, USA: American Psychological Association, 127-149.

Clark, H. H. and E. F. Schaefer. (1989). "Contributing to Discourse," Cognitive Science 13, 259-294.

Conklin, J. and M. L. Begeman. (1987). "gIBIS: A Hypertext Tool for Team Design Deliberation," in Proceedings of the Hypertext '87 Conference. Chapel Hill, North Carolina: University of North Carolina, 247251.

Courtney, J. F. (2001). "Decision Making and Knowledge Management in Inquiring Organizations: Toward a new Decision-making Paradigm for DSS," Decision Support Systems 31, 17-38.

Dillenbourg, P. (2002). "Over-scripting CSCL: The Risks of Blending Collaborative Learning With Instructional Design," in P. A. Kirschner, (Ed.), Three Worlds of CSCL: Can we Support CSCL? Heerlen, The Netherlands: Open Universiteit Nederland, 61-91.

Dillenbourg, P., M. Baker, A. Blaye, and C. O'Malley. (1995). “The Evolution of Research on Collaborative Learning," in P. Reimann and H. Spada, (Eds.), Learning in Humans and Machine: Towards an Interdisciplinary Learning Science. Oxford, UK: Elsevier, 189-211.

Douglas, M. and A. B. Wildavsky. (1982). Risk and Culture: An Essay on the Selection of Technical and Environmental Dangers. Berkeley, USA: University of California Press.

Eden, C. (1992). "A Framework for Thinking About Group Decision Support Systems (GDSS)," Group Decision and Negotiation 1, 199-218.

Eden, C. (1995). "On Evaluating the Performance of 'Wide-Band' GDSS's," European Journal of Operational Research $81-302-311$

Eden, C. and F. Ackermann. (2001). "SODA — The Principles," in J. Rosenhead and J. Mingers, (Eds), Rational Analysis for a Problematic World Revisited. Chichester, UK: John Wiley and Sons, 21-41.

Finlay, P. N. (1998). "On Evaluating the Performance of GSS: Furthering The Debate," European Journal of Operational Research 107, 193-201. 


\section{COMMON GROUND AND DECISION MAKING}

Fischer, F., J. Bruhn, C. Gräsel, and H. Mandl. (2002). "Fostering Collaborative Knowledge Construction With Visualization Tools," Learning and Instruction 12, 213-232.

Fischer, G., and J. Ostwald. (2003). "Knowledge Communication in Design Communities," in R. Bromme, F. W. Hesse and H. Spada, (Eds), Barriers and Biases in Computer-mediated Knowledge Communication. Dordrecht, The Netherlands: Kluwer Academic Publishers, 1-32.

Friend, J. and A. Hickling. (1987). Planning Under Pressure: The Strategic Choice Approach. Oxford, UK: Pergamon.

Friend, J. (2001). “The Strategic Choice Approach,” in J. Rosenhead, and J. Mingers, (Eds), Rational Analysis for a Problematic World Revisited. Chichester, UK: John Wiley and Sons, 115-149.

Goffman, E. (1959). Presentation of Self in Everyday Life. Garden City, New York: Doubleday Anchor Books.

Hasan, H. and E. Gould. (2001). "Support for the Sense-Making Activity of Managers," Decision Support Systems $31,71-86$.

Hickling, A. (2001). "Gambling with Frozen Fire?" in J. Rosenhead and J. Mingers, (Eds), Rational Analysis for a Problematic World Revisited. Chichester, UK: John Wiley and Sons, 151-180.

Kim, W. C. and R. A. Mauborgne. (1995). “A Procedural Justice Model of Strategic Decision Making,” Organization Science 6, 44-61.

Landis, J. and G. G. Koch. (1977). “The Measurement of Observer Agreement for Categorical Data," Biometrics $33,159-174$.

Langfield-Smith, K. and A. Wirth. (1992). "Measuring Differences Between Cognitive Maps,” Journal of the Operational Research Society 43, 1135-1150.

Latané, B., K. Williams, and S. Harkins. (1979). "Many Hands Make Light the Work: The Causes and Consequences of Social Loafing," Journal of Personality and Social Psychology 37, 822-832.

Leontjev, A. N. (1981). "The Problem of Activity in Psychology," in J. V. Wertsch, (Ed.), The Concept of Activity in Soviet Psychology. Armonk, USA: Sharp, 37-71.

Lomi, A., E. R. Larsen, and A. Ginsberg. (1997). "Adaptive Learning in Organizations: A System-Dynamics-Based Exploration," Journal of Management 23, 561-582.

Mulder, I., J. Swaak, and J. Kessels. (2002). "Assessing Group Learning and Shared Understanding in TechnologyMediated Interaction," Educational Technology \& Society 5, 35-47.

Noldus, L. P. J. J., R. J. H. Trienes, A. H. M. Hendriksen, H. Jansen, and R. G. Jansen. (2000). "The Observer Video-Pro: New Software for the Collection, Management, and Presentation of Time-Structured Data From Videotapes and Digital Media Files," Behavior Research Methods, Instruments \& Computers 32, 197206.

Nunamaker, J. F., A. R. Dennis, J. S. Valacich, D. R. Vogel, and J. F. George. (1991). “Electronic Meeting Systems to Support Goup Work," Communications of the ACM 34(7), 40-61.

Nutt, P. C. (2002). Why Decisions Fail. San Francisco: Berrett-Koehler.

Ostwald, J. (1996). Knowledge Construction in Software Development: The Evolving Artifact Approach. PhDThesis. University of Colorado at Boulder, Boulder, USA.

Pettigrew, A. M. (1977). "Strategy Formulation as a Political Process," International Studies in Management and Organization 7, 78-87.

Richardson, G. P. and D. F. Anderson. (1995). "Teamwork in Group Model Building," System Dynamics Review $11,113-137$.

Rittel, H. W. H. and M. M. Webber (1973). "Dilemmas in a General Theory of Planning," Policy Sciences 4, $155-169$.

Rosenhead, J. and J. Mingers. (eds). (2001). Rational Analysis for a Problematic World Revisited. Chichester, UK: John Wiley and Sons.

Rotmans, J. (1998). "Methods for IA: The Challenges and Opportunities Ahead," Environmental Modeling and Assessment 3, 155-179.

Rowe, G. and G. Wright. (1999). “The Delphi Technique as a Forecasting Tool: Issues and Analysis," International Journal of Forecasting 15, 353-375

Shaw, D., F. Ackermann, and C. Eden. (2003). "Approaches to Sharing Knowledge in Group Problem Structuring." Journal of the Operational Research Society 54, 936-948. 
BEERS ET AL.

Suthers, D. D. (2001). "Towards a Systematic Study of Representational Guidance for Collaborative Learning Discourse," Journal of Universal Computer Science 7, 254-277 Retrieved 23 January 2004, from http://www.jucs.org/jucs_7_3/towards_a_systematic_study.

Thomas, A. P., P. Bull, and D. Roger. (1982). "Conversational Exchange Analysis," Journal of Language and Social Psychology 1, 141-155.

Van Asselt, M. B. A. (2000). Perspectives on Uncertainty and Risk. Dordrecht: Kluwer.

Van Bruggen, J. M. (2003). Explorations in Graphical Argumentation; The use of External Representations in Collaborative Problem Solving. PhD-thesis, Open University of the Netherlands, Heerlen, The Netherlands.

Van de Ven, A. H. and A. L. Delbecq. (1974). "The Effectiveness of Nominal, Delphi, and Interacting Group Decision Making Processes," Academy of Management Journal 17, 605-621.

Van Someren, M. W., P. Reimann, H. P. A. Boshuizen, and T. De Jong. (eds.). (1998). Learning With Multiple Representations. Oxford, UK: Elsevier.

Vennix, J. A. M. (1996). Group Model Building: Facilitating Team Learning Using System Dynamics. Chichester, UK: John Wiley and Sons.

Verschuren, P. J. M. (1997). "Ontwerpgericht Onderzoek: Een Methodologische Bezinning [Design-based research: A methodological reflection]," Bedrijfskunde 69, 82-89.

Woltjer, G. (2003). Decisions and Macroeconomics: Development and Implementation of a Simulation Game. Research Memorandum No. rm03002, Maastricht, The Netherlands: METEOR, Maastricht Research School of Economics of Technology and Organizations; Maastricht University. 